\title{
O LAZER NO COTIDIANO: PRÁTICAS COLETIVAS COMO RESISTÊNCIA ${ }^{1}$
}

\author{
Francivaldo José da Conceição Mendes ${ }^{2}$ \\ Márcio Douglas do $\mathrm{Amaral}^{3}$
}

\begin{abstract}
RESUMO
Este trabalho discute a noção de cidade, de cotidiano, com centralidade na ocorrência do lazer. Nesse contexto o lazer é entendido como um conjunto de práticas humanas vivenciadas num tempo livre e diferenciado que coexistem temporal e espacialmente nas diferentes sociedades. O objetivo é demonstrar que em diferentes contextos espaciais vigoram variadas práticas que, a despeito de serem consideradas pouco importante, constituem-se em conteúdos significativos da vida social urbana. Essas práticas de lazer existem porque são resistência a uma lógica irredutível de poder. Em outras palavras, são expressões do cotidiano social não capturadas pela racionalidade técnica das formas urbanas e que se encontram dissociadas de um padrão que se baseia no consumo e na efemeridade das relações sociais. A reflexão aqui proposta parte de uma revisão bibliográfica combinada com reiteradas observações em campo que se deram em cidades da Amazônia e de outras regiões do Brasil. Em que pese a predominância da abstração do espaço urbano verificou-se que os sujeitos, nos diferentes tempos e espaços, mantêm uma sofisticada rede de interação e sociabilidade cuja materialidade remete a práticas espontâneas, não racionalizadas, notabilizando caminhos reais para uma cidade, um cotidiano, diferentes para e pelo lazer.
\end{abstract}

Palavras-chave: Lazer. Urbano. Cidade. Cotidiano.

\begin{abstract}
This paper discusses the notion of the city, of everyday life, with a central focus on the occurrence of leisure. In that contexto the leisure is understood as a set of human practices experienced in a free and differentiated time that coexists temporally and spatially in different societies. The objective is to demonstrate that in different spatial contexts there are various practices that, despite being considered litte important, constitute significant content of urban social life. These leisure practices exist because they re-exist to an irreducible logic of power. In other words, they are expressions of social daily life that are not captured by the technical rationality of urban forms and that are dissociated from a pattern that is based on consumption and the ephemerality of social relations. The reflection proposed here starts from a bibliographic review combined with repeated field observations that took place in cities in the Amazon and other regions of Brazil. In spite of the predominance of the abstraction of urban space, it was found that the subjects, in different times and spaces, maintain a sophisticated network of interaction and sociability whose materiality refers to spontaneous, non-rationalized practices, highlighting real paths to a city, a daily life, different for and for leisure.
\end{abstract}

Keywords: Leisure. Urban. City. Daily.

Data de submissão: 15.07 .2020

Data de aprovação: 02.09.2020

\footnotetext{
${ }^{1}$ Os resultados aqui apresentados fazem parte da pesquisa de doutorado em andamento junto ao Programa de Pós-Graduação em Geografia/UFPA, sob a orientação do Dr. Márcio Douglas Brito Amaral.

${ }^{2}$ Licenciado em Educação Física (UEPA), Mestre em Linguagens e Saberes na Amazônia (PPLSA-UFPA), Doutorando em Geografia (PPGEO-UFPA). Técnico em Assuntos Educacionais na Universidade Federal do Pará- Campus de Altamira. E-mail: francivaldo.edfisica@gmail.com.

${ }^{3}$ Doutor em Geografia-Universidade de São Paulo. Diretor da Faculdade de Geografia da Universidade Federal do Pará- Campus Guamá IFCH. E-mail: marcioamaral29@gmail.com.
} 


\section{INTRODUÇÃO}

Considera-se lazer as diferentes práticas sociais cujas ocorrências estejam diretamente ligadas a dimensões como: tempo (livre/disponível), atitude, liberdade e espaço. Sendo o lazer parte dos processos históricos e sociais sua materialidade expõe as múltiplas contradições desse movimento histórico. Daí porque, ao contrário de alguns trabalhos, não se buscar aqui a "gênese" do lazer. Isso porque, eventualmente, esse recuo pode sugerir conclusões anacrônicas. Do mesmo modo, acredita-se que explicar o tema do lazer a partir do seu aspecto semântico-etimológico constitui-se em verdadeiros limitadores a compreensão deste fenômeno. Isso porque, nos diferentes tempos e espaços, são inúmeras as práticas vivenciadas no tempo livre, o que certamente não pode ser apreendida de forma simplificada ou por elaborações teóricas estanques.

Essa ponderação, em certa medida metodológica, faz-se necessária pelo fato de que o debate atual em torno do lazer não ser ainda consensual. No Brasil e no mundo pelo menos dois grupos se notabilizaram em torno dessa discussão. $\mathrm{O}$ primeiro, assegura que as práticas que remetem ao lazer sempre existiram, são constitutivas da cultura humana. $\mathrm{O}$ segundo, considera o lazer como sendo uma construção eminentemente moderna, cujo estágio inicial corresponde a revolução industrial ocorrida na Europa.

Sem a pretensão de aprofundar esse debate, menos ainda de apresentar um parecer definitivo a seu respeito, considera-se importante evidenciar que, teoricamente, pelo menos uma parte dos estudiosos consideram como equivalente ao lazer ocorrências como: Skholé na Grécia antiga, Licere na Roma antiga para finalmente sua ocorrência atual, a forma do lazer.

Não é propósito desse trabalho problematizar esse instrumental metodológico com que se efetivam os estudos sobre a ocorrência histórica do lazer, embora prevaleça uma excessiva preocupação no estabelecimento de recortes que aprisionam espacial e historicamente determinadas práticas sociais que, notadamente, são carregadas de singularidades, de contradições históricas. Dito de outra forma, como assegurar que uma apresentação teatral na Grécia antiga tenha a mesma equivalência de uma apresentação similar na Paris dos dias atuais? De outra forma, teria equivalência entre o Skholé da Grécia e o lazer da Paris de hoje?

Daí porque, respeitando os excelentes trabalhos produzidos nesse campo, a exemplo de, Parker (1978), Dumazedier (1976), Munné (1980) e De Grazia (1966), Gomes (2005), Mascarenhas (2005) opta-se por reafirmar o pensamento de Magnani (1998) segundo o qual tão importante quanto os limites de um enquadramento terminológico, a redução de práticas complexas a respostas obtidas em questionários fechados, é considerar a expressão do lazer na sua manifestação real, no dia-a-dia, no cotidiano dos diferentes grupos. Isso não implica prescindir das diferentes temporalidades históricas, mas considerar que as expressões do lazer são espacial e temporalmente diversas o que torna arriscado eventuais generalizações cujo resultado certamente minimiza e reduz essas ocorrências.

Este trabalho, no entanto, preocupa-se em discutir as práticas do lazer para além dos formalismos de ordem etimológica, ou do seu aprisionamento em recortes históricos como se fosse possível identificar o exato momento em que o fenômeno do lazer começa a existir enquanto prática humana. Os limites que se apresentam nesse trabalho são bem menos pretensiosos e rígidos. Pretende-se considerar as diferentes vivências coletivas coexistentes em diferentes tempos e espaços cuja centralidade remete ao cotidiano, ao espaço vivido.

Dito isso e, embora se reconheça que o debate acerca da ocorrência histórica do lazer está posto e longe de consenso, este trabalho considera as práticas sociais vividas no tempo livre, dissociada do trabalho, como expressões do lazer. Tais práticas não são homogêneas, no tempo, nem no espaço. Como se demonstrará ao longo desse trabalho, as cidades são locais privilegiados para sua concretização que se dá pela ação coletiva dos diferentes sujeitos ao ocuparem os espaços e experimentarem diferentes formas de lazer. A inserção no cotidiano do 
lazer, a observação participante, entre outras técnicas da etnografia urbana, constituíram-se em importantes mecanismos para sistematização dos dados colhidos nesse estudo que ocorreu em uma cidade da Amazônia (Altamira-PA) e em outra do Sudeste brasileiro (São Paulo). No cotidiano dessas cidades as diferentes práticas evidenciam formas distintas do lazer, não devendo ser tomadas como definição acabada, haja vista ser o lazer múltiplo, orgânico e pressupor movimento.

\section{O LAZER NUMA ABORDAGEM INTERDISCIPLINAR}

Com o cuidado de não incorrermos em recortes arbitrários, mas com a certeza de que é preciso reiterar o caminho metodológico que se propõe a decifrar os nexos que dinamizam a ocorrência do lazer, compreendemos ser importantes aproximações que direcionam a compreensão a manifestação do objeto sobre o qual se investiga. Nesse caminho, os conceitos devem ser entendidos como norteadores, flexíveis, que se ajustam e se conformam, à medida que o espaço é produzido no tempo. Essa produção não é dada, é construída por e a partir das diferentes interações que os sujeitos sociais estabelecem cotidianamente.

Defendemos que o lazer, sendo uma expressão humana, encontra no cotidiano seu local privilegiado para sua materialidade. Inicialmente não está entre nossa preocupação percorrer o caminho que autores como Dumazedier (1976), Parker (1978), fizeram na tentativa de realizar uma espécie de "fatoração" da ocorrência do lazer em que a concepção percentual apresenta-se como síntese das diferentes e complexas manifestações do lazer, conforme se verifica em (DUMAZEDIER, 1976, p. 181, 301).

Considerando as pesquisas acima como um ponto de partida ${ }^{4}$, acreditamos que o cotidiano em sua expressão vivida nos fornece um parâmetro mais apurado a respeito do lazer. A esse respeito notamos uma considerável produção de conhecimento especialmente a partir da segunda metade do século XX em que autores a exemplo de Henry Lefebvre (1991) tem notoriedade. No Brasil, citamos Martins (2014) e Magnani (2018) como pesquisadores que têm dedicado boa parte da sua vida acadêmica ao estudo do cotidiano.

Especialmente no campo do lazer estudos como os de Magnani (1998, 2002, 2018), indicam-nos importantes caminhos, especialmente porque para este autor o lazer não pode ser apreendido somente pela aplicação de questionários, entrevistas fechadas, em cujo sentido metodológico repousa uma dimensão conservadora.

No entanto, devemos reconhecer que especialmente no interior da academia, essa forma de estudar a realidade a partir das ocorrências do cotidiano está longe de ser consenso. Há uma grande resistência, denunciado por Martins (2014), Magnani (1998) segundo o qual o cotidiano não guarda a permanência de fenômenos sociais que lhes dê base a uma investigação científica sólida.

Evidentemente, os autores citados acima, com os quais nos associamos, creem exatamente no oposto. São as expressões do cotidiano, sua efemeridade, que contêm boas pistas para se estudar o lazer. Esse cenário brevemente narrado traduz o desafio que envolve estudar as ocorrências do lazer. Primeiro por ser uma área de estudo relativamente recente, somado ao pouco prestígio no ambiente da chamada ciências humanas e sociais. Sobre isso Parker (1978, p. 09) referindo-se aos estudos do lazer na Inglaterra do século XX afirmou: "até poucos anos a sociologia do lazer na Grã-Bretanha [...] era tratada com zombaria- algo assim como a sociologia da bicicleta- ou como um adendo ao estudo do trabalho e da sociedade industrial".

\footnotetext{
${ }^{4}$ Não pressupõem negá-las na sua totalidade, mas compreender que estas representam um ponto de vista de vista de uma época e de um espaço diferente do que prevalece nos dias atuais. Não se trata de revanchismo teórico, mas de procurar construir uma abordagem mediando teoria e a realidade sobre a qual investigamos.
} 
O mesmo autor, porém, reconhece o avanço dos estudos do lazer bem como sua consolidação no interior da academia, tanto é que figura como componente de investigação na dita "sociologia do lazer". No entanto, o fato de ser acolhido na dita sociologia do lazer, não torna esse cenário menos desafiador, especialmente quando compreendemos que nem nas ciências sociais o estudo de determinados fenômenos a partir do cotidiano representa unanimidade.

Indiscutivelmente, no tempo atual o lazer reveste-se de relevância acadêmica com um calendário de eventos consolidados desde os anos de 1980, ampliando-se a partir dos anos $2000^{5}$, soma-se a isso o fato de figurar com um campo de conhecimento interdisciplinar especialmente com aquelas ciências que discutem a complexidade do espaço urbano. É nesse sentido que esse trabalho se constitui, considerando especialmente a relação lazer-cotidiano no espaço das cidades.

Como mencionado, tempo livre é premissa às práticas do lazer, evidentemente outras dimensões são necessárias para sua plena ocorrência, mas o tempo do lazer não é o tempo do trabalho, ainda que trabalho não seja antítese do lazer.

Os deuses tinham condenado Sísifo a rolar um rochedo incessantemente até o cimo
de uma montanha, de onde a pedra caía de novo por seu próprio peso. Eles tinham
pensado, com as suas razões, que não existe punição mais terrível do que o trabalho
inútil e sem esperança (CAMUS, 1942, p. 85).

Essa passagem nos possibilitar refletir não sobre o lazer diretamente, mas sobre a sua complementariedade: o trabalho. A proximidade e o distanciamento nesse par dialético, tem na era moderna seu ponto máximo pois, conforme Mascarenhas (2005), lazer não se materializa no tempo do trabalho.

A considerarmos o mito de Sísifo, poderíamos imaginar o quão desesperador seria a vida do personagem narrado que, tomado pela obrigatoriedade alienadora de uma tarefa, viuse destituído de qualquer prazer na sua vida, afinal encontrara-se condenado a servidão de um trabalho sem sentido e sem fim. Essa analogia, ainda que incipiente, nos fornece um parâmetro para refletirmos acerca das características que imperam no mundo do trabalho e que por isso, influenciam diretamente nas práticas do lazer.

Se trabalho é condição para compreendermos as relações sociais da humanidade, tempo é uma dimensão necessária a compreensão do lazer. Da relação entre tempo e trabalho surgem importantes determinações para que se compreenda a ocorrência do lazer, aqui entendido para além de disputas semântico-etimológicas. $O$ tempo do lazer não pode ser o mesmo do trabalho, sem os quais (tempo e trabalho) se torna impossível entender a anatomia das práticas do lazer.

O lazer na/da cidade, não pressupõe ou não deveria pressupor hierarquias, onde um elemento figure com gênero e/ou espécie do outro. Entre essas duas dimensões (o lazer e a cidade) não há que se considerar sobreposição, isso porque, o lazer sobre o qual falamos deve ser entendido como expressão orgânica da subjetividade e, sobretudo, de relações coletivas presentes na cidade.

Visto dessa forma, não se trata de elidir a dimensão histórica e sucumbir ao imediatismo da aparência que asfixia a abstração, limitando a compreensão das determinações históricas. Ao contrário disso, acreditamos que o lazer, pelo cotidiano deve ser considerado sob quatro dimensões: tempo, atitude e liberdade, espaço. Tempo é aquele livre das obrigações do trabalho, o trabalho não somente entendido na sua dimensão estrita formal, da fábrica, a liberação é de qualquer forma de trabalho. A atitude refere-se a iniciativa que parte do sujeito nesse tempo livre, pressupondo espontaneidade. A liberdade refere-se à

\footnotetext{
5 A exemplo do "Seminário: o lazer em debate" e do "Congresso Brasileiro de Estudos do Lazer".
} 
possibilidade de escolha de que o sujeito dispõe em, pelo menos, duas situações reais. $\mathrm{O}$ espaço não é somente o físico, o absoluto, refere-se também a um conjunto de práticas socialmente constituídas que, constituindo relações sociais, constituem os sujeitos nas suas práticas cotidianas ${ }^{6}$.

Essa inserção anterior cumpre uma finalidade de parâmetro, haja vista conforme já demonstramos, definir precisamente determinado fenômeno social é assumir a tarefa de tornar estático aquilo que por natureza é dinâmico. Queremos dizer, no entanto, que sendo o lazer parte dessa dinâmica, desse movimento que compõem a história humana, aplica-se a ele essa transitoriedade e relatividade com que nos referiremos quanto a sua ocorrência e definição, em síntese: o lazer não é um fenômeno acabado, mas em permanente transformação.

Sendo um fenômeno, encontra na informalidade do espaço banal, na contra racionalidade do cotidiano, na ordem próxima, seu espaço privilegiado de ocorrência. É a subversão da ordem instituída, da razão espacial, dos conteúdos, das formas. Tal fenômeno opõem-se às amarras formalistas da tecnocracia a que se referiu Lefebvre (2006).

Nesse sentido, o lazer precisa ser visualizado, como uma expressão que emana das múltiplas relações sociais, devendo ser observado como obra humana, como projeto coletivo, ou parafraseando Lefebvre (2001), numa utopia.

O lazer a que nos referimos é expressão das ruas, dos bares, dos campos de várzea, das mesas de dominó do fim de tarde, dos pedaços, das manchas, para usar duas expressões de Magnani (2002). Esse lazer, invisibilizado pela modernidade, suplantado pela dimensão mercadológica e que, no caso dos projetos na Amazônia soma-se a uma perversa descaracterização dos conteúdos e formas da vida cotidiana, subsiste na apropriação dos diversos espaços dispersos pela cidade. Lazer aqui não deve ser entendido numa dimensão limitadora, associado a uma perspectiva funcionalista ${ }^{7}$.

O trabalho, condição fundante da existência humana, para usar uma expressão Marxiana, embora não seja categoria central desse debate, concorre na conformação e materialidade do lazer. Isso porque para autores como Dumazedier (1999) não se pode falar em prática do lazer se persistir, qualquer que seja, obrigação laboral. Essa afirmação, atualmente, apresenta um grande desafio que é compreender a crescente mercantilização do lazer, onde na sociedade espetáculo; lazer é trabalho e trabalho é lazer.

A considerarmos a sucessão do tempo histórico, sem a intenção de reduzir anacronicamente a história da humanidade, dois acontecimentos têm fortes conexões com o tempo de trabalho, tempo de não trabalho, tempo livre/disponível, ressaltando, porém, que embora haja uma corrente teórica que considera o lazer como manifestação inerente a própria história humana, temos optado por considerar o movimento que acompanha historicamente a ocorrência do que temos chamado de lazer, sem uma rígida definição conceitual/temporal.

O primeiro desses acontecimentos, foi a domesticação da agricultura, fato que se olhado por outro prisma acabou por domesticar o ser humano que se viu impedido de deslocar-se com mais liberdade pelo espaço, haja vista as inúmeras responsabilidades como cuidar do solo, das plantações, estando pois, subordinado às intempéries naturais e, por isso, destituído de maior liberdade no seu tempo livre, agora significativamente reduzido.

A segunda grande mudança ocorreu com a chamada revolução industrial, contexto em que houve uma ruptura nos modos de organização social, sobretudo relativa à vida nas cidades. Essa mudança se deu em função da transição do então modelo agrário-rural para o urbano industrial. Enguita (1989), destaca as fugas em massa de pessoas que se negavam a submeter-se ao modelo de trabalho e a organização social recém impostos. Evidentemente, na

\footnotetext{
${ }^{6}$ Essa noção baseia-se em Dumazedier (1976) e Lefebvre (1991)

${ }^{7}$ Essa visão funcionalista é descrita por Marcellino (1987) como sendo composta por quatro diferentes vertentes: romântica, moralista, compensatória ou utilitarista.
} 
contramão dessas ações, instaurou-se um conjunto de medidas repressivas por parte dos que detinham o controle econômico e político.

No mesmo sentido, Melo (2003), apresenta um conjunto de evidências históricas ocorridas nas fábricas com repercussões profundas no modo de vida das pessoas. Medidas como a inserção do "ponto", a obrigação da fiel obediência ao horário cronometrado, foram algumas das medidas tomadas naquele contexto que impactaram diretamente o tempo do trabalho e o tempo disponível.

Esse acirramento entre o tempo do trabalho, e o tempo do não trabalho, que não necessariamente é o tempo disponível, certamente é um imperativo a compreensão das diferentes formas do lazer. Se tempo livre é condição ao lazer, ter tempo livre não implica vivenciar o lazer. Na ordem capitalista essas contradições sinalizam o crescente desafio que é a fruição do lazer nas cidades, no cotidiano.

\section{A MODERNIDADE, O LAZER E AS CONTRADIÇÕES DAS CIDADES CAPITALISTAS}

Nesta modernidade, de acordo com Debord (1997), o lazer compõe a sociedade do espetáculo, cuja mediação social baseada no capitalismo passa a ser a imagem. Essa lógica do capitalismo expropria os sujeitos de um tempo disponível, do usufruto do lazer enquanto prática que promova o desenvolvimento humano. Ao contrário disso, a indústria cultural expande-se, apropriando-se de determinados mecanismos tornando o lazer mera mercadoria.

Esses polos equidistantes e convergentes (o lazer e o trabalho) a que nos referimos, diz respeito ao caráter cada vez mais alienador do trabalho como plataforma do lazer e do lazer como fundamento do trabalho, senão vejamos o que são os megaeventos esportivos ocorridos recentemente no Brasil $^{8}$, ou a espetacularização de práticas oriundas do cotidiano pelas inúmeras cidades da Amazônia, sobre o que Lefebvre (1991, p. 71) alertava: "o espetáculo do mundo, torna-se consumo de espetáculo e espetáculo do consumo, o que fornece um bom exemplo de torniquete, uma espécie de pleonasmo que os racionalistas da organização tomam por um equilíbrio".

Sobre esse espetáculo do mundo, base do espetáculo do consumo, destacam-se no Brasil diversos exemplos de como as cidades são modificadas em função do lazer. Azevedo e Faulhaber (2015) apresentam algumas dessas mudanças ocorridas na cidade do Rio de Janeiro por ocasião das Olimpíadas e da Copa do Mundo de futebol em 2016 e 2014, respectivamente. Tais intervenções, basearam-se na ideia da produção do lazer como fundamento do espetáculo consubstanciado numa pseudo democratização dos espaços públicos.

\footnotetext{
${ }^{8}$ Referimo-nos a Copa do Mundo de Futebol da FIFA (2014) e das Olimpíadas (2016), ambos realizados na cidade do Rio de Janeiro.
} 
Figura 1- Remoções no Rio de Janeiro em 2012

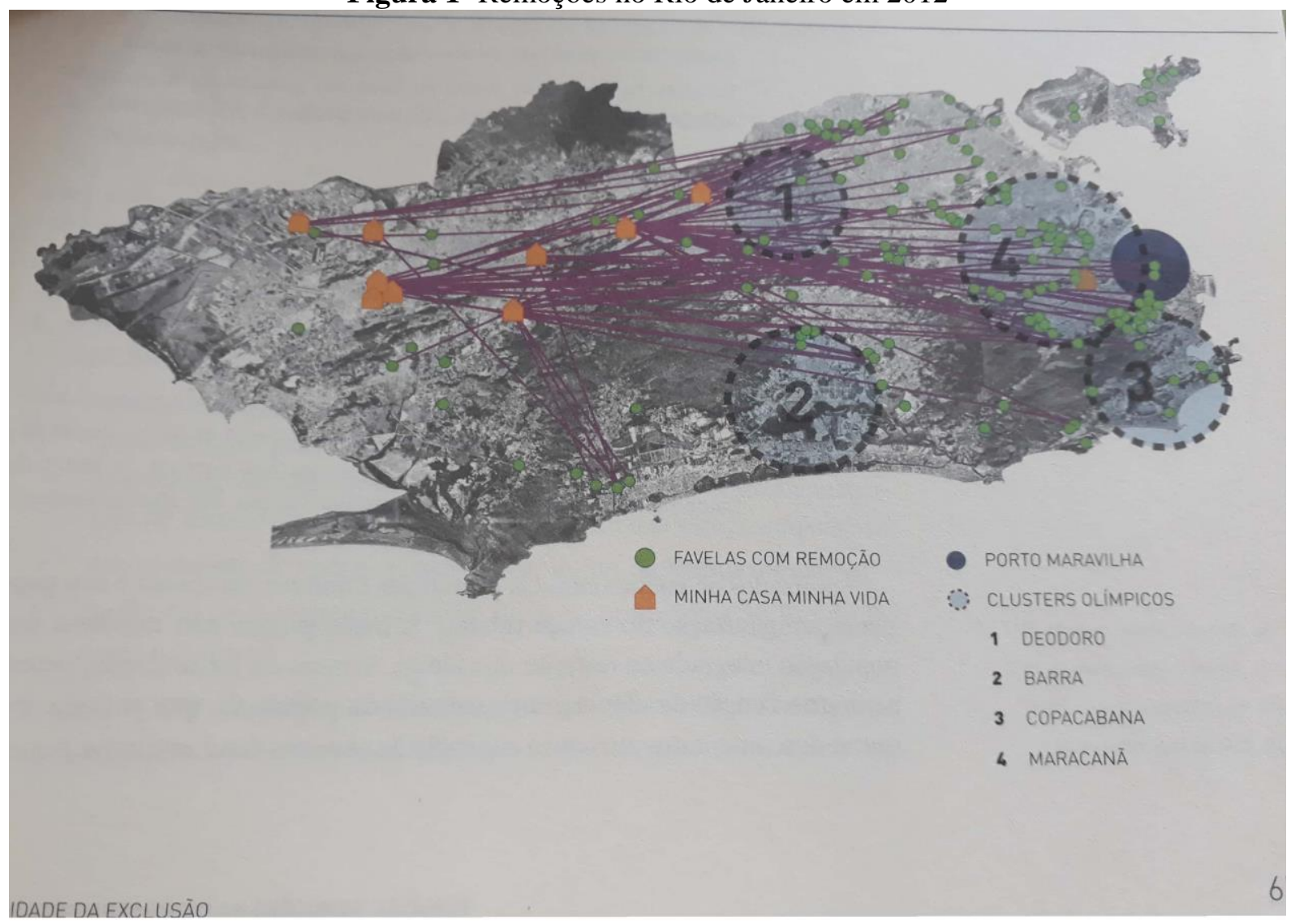

Fonte: Azevedo e Faulhaber (2015, p. 67)

A produção do espaço está submetida a uma ideia global que retira as singularidades locais incorporando essa atmosfera racional, pré-concebida. O lazer nesse contexto é ingrediente desse receituário neoliberal cujo sentido expressa aquilo que Lefebvre (1991) destacou como sendo a "sociedade do consumo dirigido". Nesse contexto, o lazer não é mais festa, sucumbe a lógica do espetáculo, mercantilizado, racionalizado. Pelo exemplo extraído da imagem, a cidade cumpre um papel de palco, de receptáculo à efetivação de uma ordem supra local que se viabiliza na lógica capitalista.

Na Amazônia, em específico na cidade de Belém e mais recentemente em AltamiraPA, podemos notar essas interferências da lógica capitalista no cotidiano do lazer. Tal cenário remete a profundas intervenções na dinâmica das cidades o que consequentemente reverbera no modo de organização das pessoas. É dessa forma que as cidades brasileiras estão estruturadas para o lazer, isto é, uma lógica que privilegia o espaço como invólucro do consumo e que por isso mesmo retira deste a possiblidade do encontro público pleno.

Dessa forma, o caráter formalista dos espaços acaba por atomizar as relações neles estabelecidas, fundamentando uma dimensão objetivista que no fim destitui o real sentido do espaço público como lócus de integração. Na cidade capitalista, a conformação desses espaços serve à própria lógica da reprodução do capitalismo, pela produção do espaço. Intervenções como as executadas em Paris do século XIX por Haussmann, ou as efetuadas na cidade Belém sob a gestão do Intendente Antônio José de Lemos no início do século XX, são exemplos que evidenciam formas e conteúdo orientados por uma concepção abstrata das espacialidades do lazer.

Dito isso, podemos afirmar que a predominância do lazer na cidade capitalista é mercantil, pois ações como as implementadas em Belém em espaços como a "Estação da docas", "o mangal das garças," o "Parque estadual do Utinga", entre outros retroalimentam 
uma produção capitalista travestida de uma aparente democratização do seu uso, quando na verdade o que se percebe é o esvaziamento do seu sentido público.

O agendamento prévio do Projeto Visita Monitorada deve ser feito por meio do endereço eletrônico agendamento@mangalpa.com.br. A ação é uma realização da OS Pará 2000, que além de administrar o Mangal é responsável pela gestão do Parque Estadual do Utinga, local onde também é possível agendar visitas. (AGÊNCIA PARÁ, 2019).

Essa racionalidade dos espaços nas cidades é um imperativo atual, mas que guarda relações com a própria conformação das cidades ao longo do tempo. Ao tratar das cidades Lefebvre (2001) apresenta uma espécie de "linha do tempo" na qual a cidade industrial congrega quase que a totalidade das características brevemente mencionadas, estágio em que a produção industrial superpôs-se a trocas comerciais, acentuando o êxodo rural, e consequentemente a ampliação do tecido urbano. De maneira didática o autor estrutura essas etapas da seguinte forma:

\begin{tabular}{l|l|l|l} 
Cidade política & Cidade do comércio & Cidade industrial & Zona crítica \\
\hline
\end{tabular}

Lefebvre (2001, p. 78)

Há nesse sentido uma convergência entre os estudos de Mascarenhas (2005) e Lefebvre (2001), segundo os quais a revolução industrial marca a instauração do urbano e do lazer como fenômenos. Em Mascarenhas (2005), o lazer conforme conhecemos hoje é efeito da lógica capitalista que a tudo busca transformar em mercadoria, em consumo. $\mathrm{O}$ "mercolazer" é a expressão utilizada por Mascarenhas (2005) para designar a mercantilização de práticas e atividades de lazer.

Lefebvre (1991), entretanto, denomina essa realidade de "espetáculo generalizado", onde a linguagem enquanto código referencial exerce um papel de destaque na transformação de uma prática cotidiana em espetáculo do consumo, diz ele: "O lazer não é mais a Festa ou a recompensa do labor, também não é ainda a atividade livre que se exerce para si mesma. É o espetáculo generalizado: televisão, cinema, turismo" (LEFEBVRE, 1991 p. 62).

É assim, na cidade industrial, ou no seu limite, na zona crítica, que as cidades se estruturam consolidando características voltadas à privatização de espaços e de direitos, como é o caso do lazer. Tais elementos estão baseados na linguagem enquanto elemento discursivo. A cidade capitalista industrial é revestida desse caráter privatista, mercadocêntrico, ou nas palavras de Carlos, Santos e Alvarez (2018) "espaço mercadoria", que se consolida como extensão da propriedade privada em que o valor de uso subordina-se ao valor da troca. 
Figura 2- Balsa "catamarã no rio Xingu em 2018

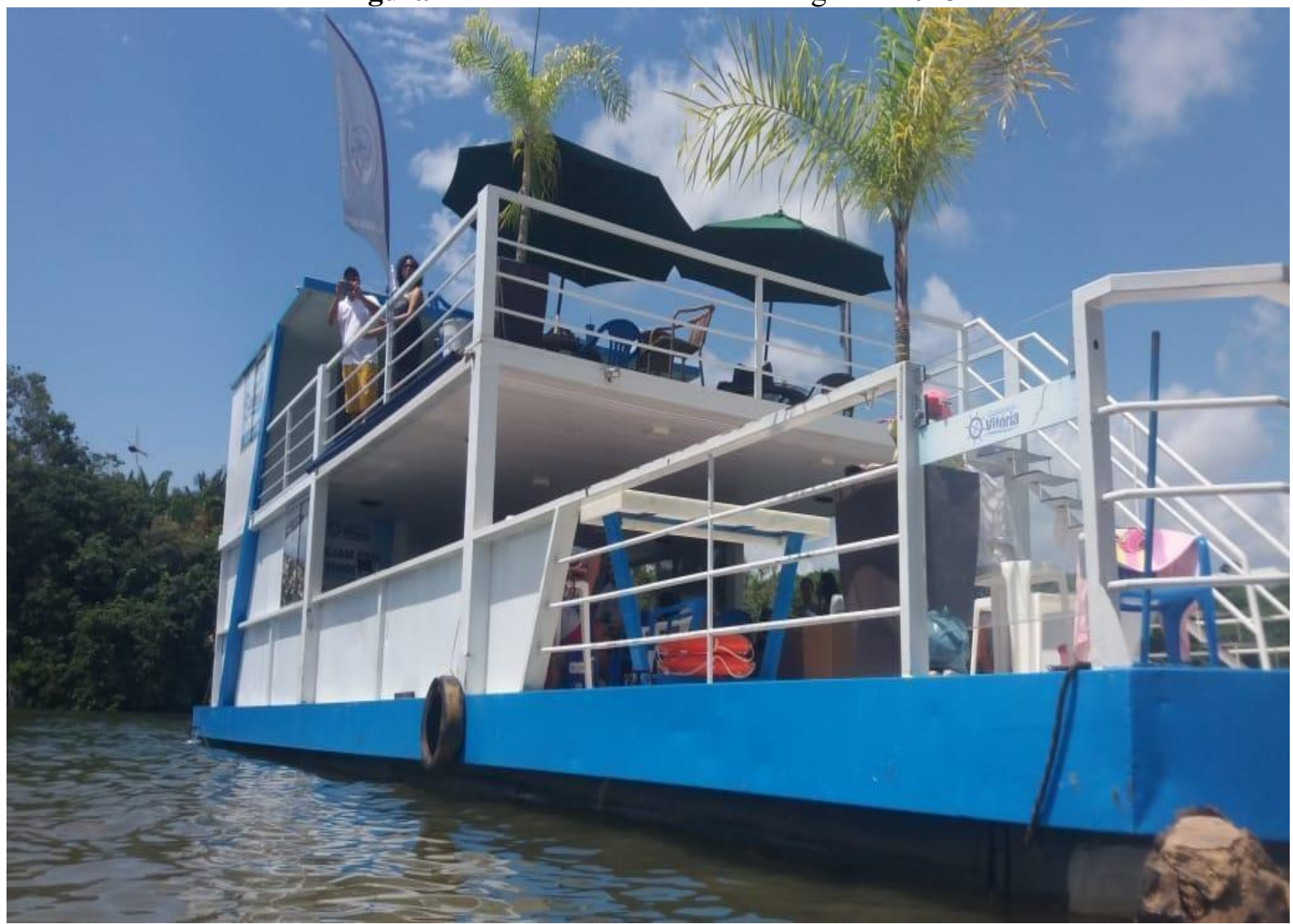

Fonte: arquivo pessoal (2018)

$\mathrm{Na}$ Altamira atual, a cidade fisicamente ficou difusa, característica que em certa medida norteou práticas do lazer emergentes no advento da Usina Hidrelétrica Belo Monte $(\mathrm{UHBM})^{9}$. A relação como a cidade e com o rio assumiram novas configurações, muito embora "rugosidades", para usar uma expressão de Santos (1982), permaneçam na cidade. Mesmo assim, o deslocamento do circuito de bares e restaurantes para o bairro do Premém, retirou a centralidade da orla da cidade como espaço articulador de relações do lazer.

Do mesmo modo, conforme se verifica pela figura 2, o rio Xingu passa a concentrar outras práticas antes não presentes como é o caso do Catamarã, balsa estilizada pela qual se paga um valor que varia entre um mil e quinhentos a dois mil e quinhentos reais por sete horas de passeio no Xingu. Dessa nova realidade, muito mais mercantilizada, destacam-se características bastantes peculiares como é o caso de, às vezes, determinadas pessoas irem ao passeio e sequer banharem no rio. $\mathrm{O}$ rio assume um papel de receptáculo, passivo, de espaço artificializado e espetacularizado pelos "selfs", "curtidas e postagens".

\section{DO LAZER NA CIDADE À CIDADE DOS LAZERES}

Partindo do pressuposto que o direito ao lazer, enquanto prática e expressão na cidade, deve ser analisado como uma totalidade, como algo que não passa pela formalidade o Estado , pois é obra humana, convém destacar que o lazer sobre o qual dissertamos não é somente aquele normatizado, programado, mercantilizado. Este, emerge das práticas cotidianas, das

\footnotetext{
9 A Usina Hidrelétrica "Belo Monte" (UHBM), iniciada em 2011, no rio Xingu, provocou profundas transformações nas relações dos sujeitos com espaços urbanos, sobretudo no município de Altamira-PA, o mais atingido pelo empreendimento. Nesse município pelo menos 22 mil pessoas foram compulsoriamente removidas das suas moradias e realocadas para os Reassentamentos Urbanos Coletivos (RUCs).
} 
manifestações coletivas dispersas pelos vários pontos da cidade que não foram capturadas pela reprodução da vida cotidiana. A cidade do lazer, é uma cidade utópica, pois esse direito seria expressão da própria conformação da urbe, onde a apropriação dos espaços, pela dimensão do vivido ganha notoriedade. Assim, lazer é expressão do espaço banal, ou do cotidiano conforme já afirmou Lefebvre (1991, p. 30) "o estudo da vida cotidiana oferece um ponto de encontro para as ciências parcelares e alguma coisa mais. Mostra o lugar dos conflitos entre o racional e o irracional na nossa sociedade e na nossa época".

Sendo o cotidiano a interseção entre o racional e o irracional, aqui entendido como a dimensão hegemonizadora e contra hegemônica, respectivamente, é válido destacar o conjunto de práticas e valores que emergem nessa contra racionalidade do lazer. Tais ações estão dispersas pelo que Leite (2002) denominou de contra-usos do espaço, que nada mais são do que formas originais com que os sujeitos atribuem usos não normatizados aos espaços formais. Certamente, tais usos derivam de uma contraposição ao estabelecimento de padrões feitos por entes, a exemplo do Estado. Esses contrausos, em certa medida, subvertem o objetivo inicial de um determinado espaço da cidade que em geral pode suscitar tensões e conflitos com o Estado ou mesmo com outros grupos. Um exemplo acontece na Avenida Paulista, em São Paulo, aos domingos.

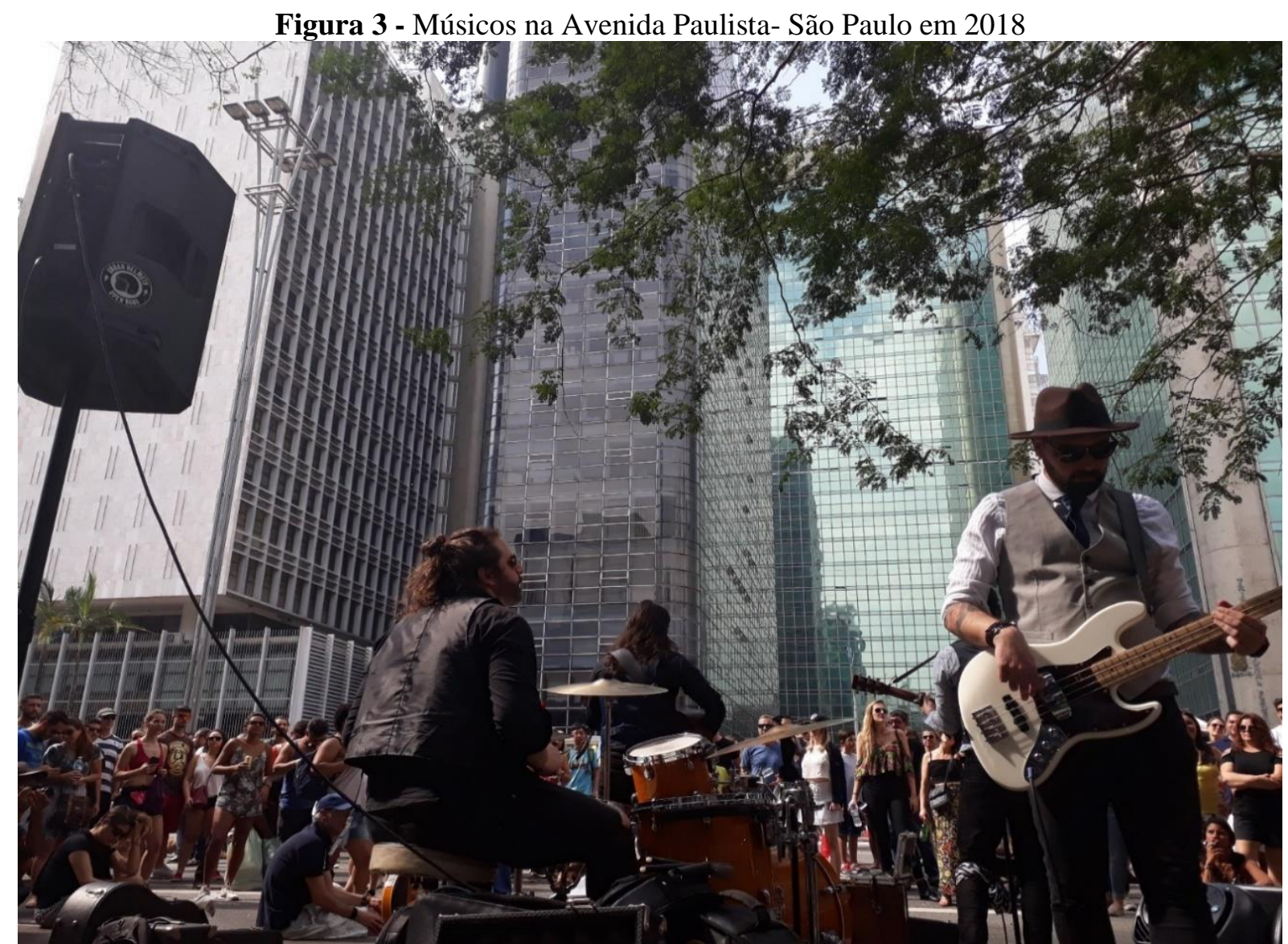

Fonte: arquivo pessoal (2018)

Falamos isso para destacar as contradições, mas também as múltiplas formas com que os sujeitos se apropriam dos espaços de lazer nas cidades. Em Altamira, conforme na avenida paulista, a praça da Independência é um espaço que articula uma série dessas características contraditórias projetando ao mesmo tempo práticas representativas, ainda que sob a vigilância formal. O sistema de monitoramento por câmeras, as grades em certos pontos acima de cinco metros de altura, o acesso ao espaço restrito a apenas um portão evidenciam, por um lado, o 
poder ordenador com que os diversos entes do Estado exercem seu controle neste espaço e, de outro, as transgressões com que se materializa práticas contra hegemônicas do lazer na cidade. As práticas mantidas pelos poetas marginais, os grupos neopentecostais, a comunidade das escolas da educação básica, das atividades do ensino superior, entre outras, fornecem pistas para entendermos o mosaico de atividade que se colocam na contramão do uso hegemônico do espaço, ou aquilo que Leite (2002) chamou de contra-usos.

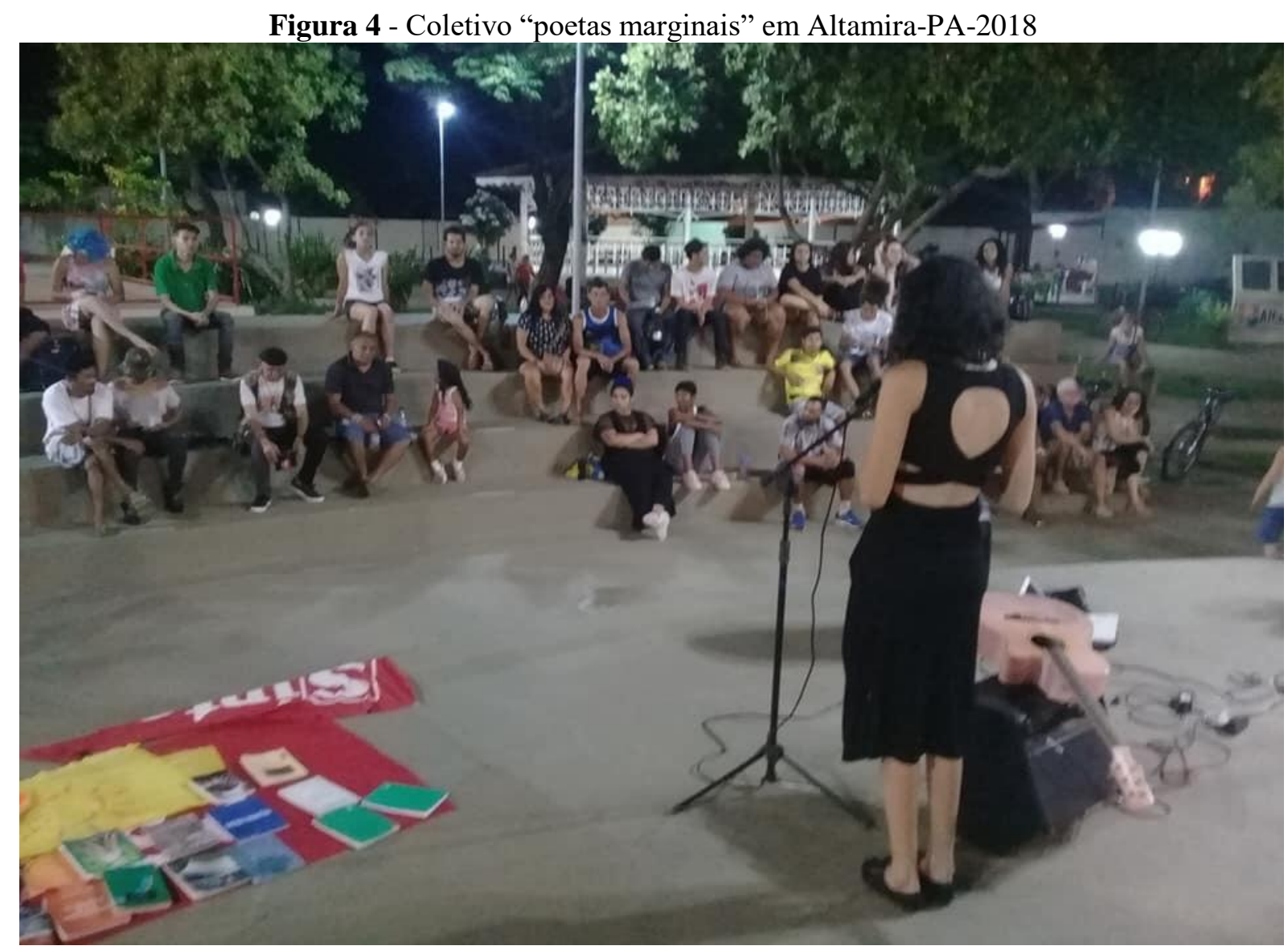

Fonte: facebook-https://www.facebook.com/coletivodepoetasmarginais/?ref=page_internal

Essas práticas informais e não hegemônicas estão dispersas ao longo de todo o tecido da cidade. Em geral passam desapercebidas diante do nosso olhar quase sempre "de fora e de longe", para usar uma expressão de Magnani (2002). O contraponto dessa lógica é aquilo que o autor chamou "de um olhar de perto e de dentro", sendo então possível, no caso de Altamira, observar a subversão do uso dado ao porto do pepino, a transposição que liga a avenida Perimentral ao RUC são Joaquim, as múltiplas apropriações do rio que sugerem as fluvialidades, as ruas estreitas apropriadas pelos diversos coletivos de ciclistas, os pontos de baralho, damas e dominó, que em manchas dispersas pela cidade formam um circuito extremamente sofisticado, com horários e pontos específicos de início e fim. Eis uma relação orgânica do lazer na cidade.

$\mathrm{Na}$ cidade, essas ações revelam processos e conteúdos que ocorrem como resistência, como antítese de uma ordem instituída, como interlocução irredutível do poder ordenador. A utopia do lazer reside na medida em que, mesmo diante dessas características objetivistas e formais na cidade, coexistem práticas aparentemente dispersas, mas que, contrariamente, encontram-se conectadas pelas manchas da cidade ou aquilo que Santana, Rechia e Rodrigues (2017) denominaram de "brechas da cidade". 
Figura 5- Banhistas na Praia artificial do "Massanori"- Altamira-PA.

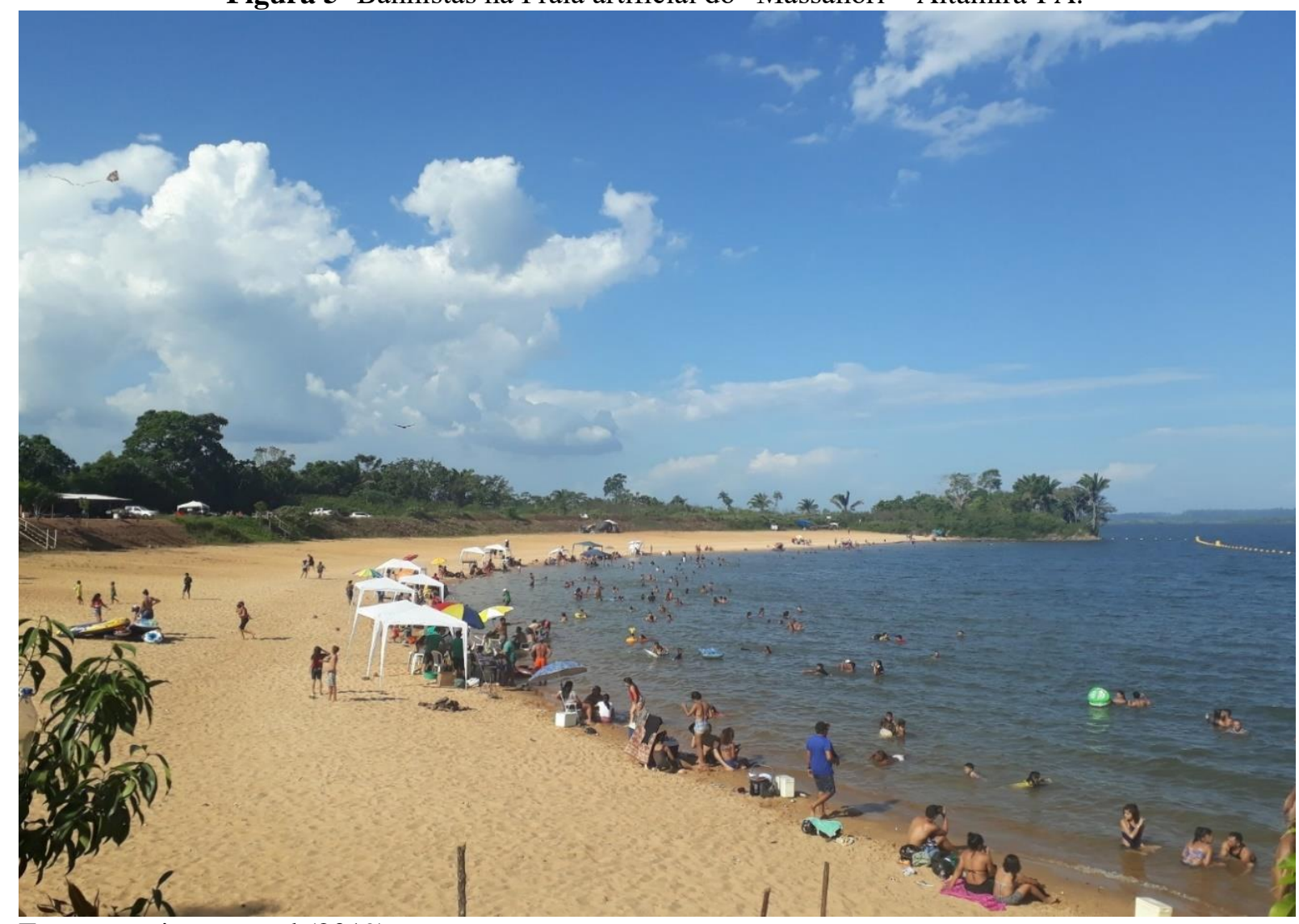

Fonte: arquivo pessoal (2019)

A praia do Massanori em Altamira-PA constitui-se em um nexo espacial que articula diferentes práticas e sujeitos da cidade e do seu entorno. Há uma lógica estabelecida nessas relações que sugerem pertencimento ao espaço, relações sociais densas, e práticas que se dão de forma não programada, não racionalizada. Em Altamira-PA, e no caso descrito em São Paulo, ainda que as práticas ocorram em espaços ordenados seus conteúdos subvertem essa condição estabelecida. Ao não serem capturadas pela reprodução da lógica capitalista as experiências do lazer contidas no cotidiano constituem-se em resistência, em marcas irredutíveis de uma vasta e sofisticada rede de relações sociais que não estão aparentes a um "olhar de fora e de longe".

\section{CONSIDERAÇÕES FINAIS}

No tempo atual, prevalece a visão hegemonizadora com que se efetivam as formas urbanas cuja finalidade é conter e ordenar práticas coletivas espontâneas. Soma-se a isso, a perda progressiva da possibilidade de fruição da vida no tempo livre, conforme descrito no mito de Sísifo. A uberização e o home office são marcas dessa precarização da vida moderna que implica no domínio do lazer. Soma-se a este cenário a imposição de uma cultura hedonística que apresenta o lazer como um produto, cujo sentido reside no consumo indiscriminado.

Assim, moderna e preponderantemente, o lazer está subordinado a um discurso, a uma dinâmica racionalizadora dos espaços e de seus conteúdos, fundamentados numa visão tecnocrática. Esta modernidade, erigiu-se sobre uma estrutura que nega os elementos do 
cotidiano e privilegia a padronização, o consumo, a racionalidade espacial. Tais características correspondem a dimensão mais aparente do lazer, abundantemente objeto de estudos e reflexões.

O contraponto a essa dinâmica, objeto desse trabalho, reside nos contra-usos que se dão pelas práticas não programadas, não racionalizadas, não capturadas pela abstração dos espaços e que por isso não estão aparentes. São práticas diferenciadoras que se mantém nos domínios do vivido. Subsistem na apropriação dos espaços e na vivência da cidade considerada obra inconclusa. Por isso, acreditamos que o lazer, enquanto prática e manifestação social, encontra no cotidiano seu lócus privilegiado. Sua manifestação materializa-se a partir de ações aparentemente simples ou o que Lefebvre (2006) denominou de espaço banal.

Resistem como antítese dessa lógica irredutível de poder, práticas espontâneas que se dão no interior do espaço banal, e se materializam na confluência e interseção dos pedaços e das brechas dispersos pela cidade. Esse lazer não programado, baseado no contra-uso, pode ser base para a transição do lazer na cidade para a cidade dos lazeres.

\section{REFERÊNCIAS}

CAMUS. Albert. O Mito de Sísifo. s.n.r. 1942.

CARLOS Ana Fani Alessandri; SANTOS, César Simoni; ALVAREZ, Isabel Pinto.

Geografia urbana crítica: Teoria e método. São Paulo: Contexto, 2018.

DE GRAZIA, Sebastian. Tiempo, trabajo y ocio. Madrid: Tecnos, 1966.

DEBORD, Guy. A sociedade do espetáculo: comentários sobre a sociedade do espetáculo. Rio de Janeiro: Contraponto, 1997.

DUMAZEDIER, Joffre. Lazer e cultura popular. São Paulo: Perspectiva, 1976.

DUMAZEDIER, Joffre. Sociologia empírica do Lazer. [Tradução: Silvia Mazza e J. Guinsburg]. São Paulo: Perspectiva, 1999.

ENGUITA, Mariano Fernándes. A face oculta da escola, o trabalho atual como forma histórica. Porto Alegre: Artes Médicas sul, 1989.

FAULHABER, Lucas, AZEVEDO, Lena. Remoções no Rio de Janeiro olímpico. Rio de Janeiro: Mórula, 2015.

GOMES, Christianne; AMARAL, Maria Teresa Marques. Metodologia da pesquisa aplicada ao lazer. Brasília: SESI/DN, 2005.

LEFEBVRE, Henry. A produção do espaço. Trad. Doralice Barros Pereira e Sérgio Martins (do original: La production de l'espace. 4e éd. Paris: Éditions Anthropos, 2000). Primeira versão: início - fev.2006.

LEFEBVRE, Henry. A vida cotidiana no mundo moderno. São Paulo: Ática, 1991.

LEFEBVRE, Henry. O direito à cidade. São Paulo: Centauro, 2001. 
LEITE, Rogerio Proença. Contra-usos e espaço público: notas sobre a construção social dos lugares na Manguetown. RBCS, Vol. $17 \mathrm{n}^{\circ}$. p.115-134. v.49. junho/2002. Disponível em:

https://www.scielo.br/scielo.php?pid=S010269092002000200008\&script=sci_abstract\&tlng= pt. Acesso em 30 out. 2019.

MAGNANI, José Guilherme Cantor. Festa no pedaço: cultura popular e lazer na cidade. 3. ed. São Paulo: Hucitec, 1998.

MAGNANI, José Guilherme Cantor. De perto e de dentro: notas para uma etnografia urbana. Revista Brasileira de Ciências Sociais, vol. 17, n. 49. p. 1-34. São Paulo, junho de 2002. Disponível em:

https://www.scielo.br/scielo.php?pid=S010269092002000200002\&script=sci_abstract\&tlng= pt. Acesso em 30 out. 2019.

MAGNANI, José Guilherme Cantor. Do mito de origem aos arranjos desestabilizadores: notas introdutórias. In: Organizadores Magnani, José Guilherme Cantor; Spaggiari, Enrico. Lazer de perto e de dentro: uma abordagem antropológica. São Paulo: Edições Sesc São Paulo, 2018. P. 12-34.

MARCELLINO, Nelson Carvalho. Lazer e Educação. Campinas: Papirus, 1987.

MARTINS, José de Sousa. Uma sociologia da vida cotidiana: ensaios na perspectiva de Florestan Fernandes, de Wright Mills e de Henry Lefebvre. São Paulo: Contexto, 2014.

MASCARENHAS, Fernando. Entre o ócio e o negócio: teses acerca da anatomia do lazer. 2005. Tese (Doutorado em Educação Física) - Faculdade de Educação Física, Universidade Estadual de Campinas, Campinas, 2005.

MELO, Vitor Andrade de. Lazer e minorias sociais. São Paulo: Ibrasa, 2003.

MUNNÉ, Frederic. Psicosociología del tiempo libre: un enfoque crítico. México: Trillas, 1980.

PARKER, Stanley. A sociologia do lazer. Rio de Janeiro: Zahar, 1978.

PASTANA, Beatriz. Visita guiada é a opção de programação no Mangal das Garças. Agência Pará, 2019. Disponível em: https://agenciapara.com.br/noticia/13763/. Acesso em 30 out. 2019.

SANTANA, Daniella Tschöke; RECHIA, Simone; RODRIGUES, Emília Amélia Pinto Costa. As brechas da cidade: a praça de bolso do ciclista da cidade de Curitiba/PR. Movimento: revista de Educação Física da Universidade Federal do Rio Grande do Sul, Porto Alegre, v. 23, n. 1, p. 311-324, jan./mar. de 2017. Disponível em: https://seer.ufrgs.br/Movimento/article/view/66384/41034. Acesso em 30 out. 2019.

SANTOS, Milton. Espaço e Sociedade. 2. ed. Petrópolis: Editora Vozes, 1982. 